\title{
In Situ Electron Backscatter Diffraction Analysis for Microstructure Evolution and Deformation Models of Mg-Ce Alloy During Uniaxial Loading
}

\author{
Fang-Wei Jiao ${ }^{1} \cdot$ Li Jin $^{1} \cdot$ Jie Dong ${ }^{1} \cdot$ Feng-Hua Wang ${ }^{1}$ \\ Received: 6 September 2018 / Revised: 29 November 2018 / Published online: 18 December 2018 \\ (c) The Chinese Society for Metals (CSM) and Springer-Verlag GmbH Germany, part of Springer Nature 2018
}

\begin{abstract}
Previous studies showed that significant increases in elongation in $\mathrm{Mg}-\mathrm{Ce}$ alloys due to the Ce addition and the solute drag effect by $\mathrm{Ce}$ addition were ascribed to the non-basal dislocation slip activating and the texture altering. The microstructure evolution and deformation models of extruded $\mathrm{Mg}-0.5 \mathrm{wt} \% \mathrm{Ce}$ alloy rods under uniaxial tension have been studied using in situ electron backscatter diffraction. The basal and non-basal slips were characterized by using slip line trace analysis. The results provide evidence for that pyramidal slip activated during deformation, besides basal slip and extension twinning, which contributes to the texture weakening and ductility increasing in $\mathrm{Mg}-0.5 \mathrm{wt} \% \mathrm{Ce}$ alloy.
\end{abstract}

Keywords Texture $\cdot$ Non-basal slip $\cdot$ Twinning $\cdot$ In situ electron backscattered diffraction (EBSD) $\cdot$ Trace analysis

\section{Introduction}

Magnesium alloys have much less formability than steel or aluminum alloys at room temperature due to their hexagonal (hcp) crystal structure with limited slip systems. There are increasing attempts to enhance the workability and ductility of magnesium alloys by grain refinement, alloying and texture modification [1-5] to overcome the inherent limitation. The texture of $\mathrm{Mg}$ alloy could be randomized by $\mathrm{Y}, \mathrm{Nd}$, Gd and Ce additions [3,5-10] as reported, and the elongation of $\mathrm{Mg}-\mathrm{Ce}$ extruded rods at room temperature could be drastically improved to $32 \%$, which was ascribed to that the $\mathrm{Ce}$ addition altering the texture and therefore basal slips is more easily operated [3]. Texture modification had actually contributed to the ductility improvement in $\mathrm{Mg}$ alloys due to the high Schmid factors of basal $\langle a\rangle$ slip [11]; however, twinning and $\langle c+a\rangle$ slip, which can provide the strain along [0001] axis, were considered to be necessary deformation model for the compatibility of $\mathrm{Mg}$ alloys [12]. While

Available online at http://link.springer.com/journal/40195

Li Jin

j_jinli@sjtu.edu.cn

1 National Engineering Research Center of Light Alloys Net Forming, School of Material Sciences and Engineering, Shanghai Jiaotong University, Shanghai 200240, China the critical resolved shear stress (CRSS) for $<c+a>$ slip in magnesium is about 2.5 times higher than that for $1 / 3<11$ $20>$ basal slip [13], the $\langle c+a>$ slip should be more difficult activated during deformation in pure $\mathrm{Mg}$ or AZ31 alloy at room temperature. Chino et al. reported that the unique compression behavior of $\mathrm{Mg}-0.2 \% \mathrm{Ce}$ was ascribed to non-basal slips [14], and more discussion had been focused on the solute drag effect with rare earth addition in $\mathrm{Mg}$ alloy and then its effect on the activation of non-basal dislocation slip [15]. However, the deformation models of $\mathrm{Mg}-\mathrm{Ce}$ binary alloy are still unclear, and it is interesting to characterize the deformation models during deformation, and the results could help to understand the reason for the texture evolution and ductility improvement in $\mathrm{Mg}-\mathrm{Ce}$ alloy.

The present work aims to study the deformation models of $\mathrm{Mg}-0.5 \mathrm{wt} \% \mathrm{Ce}$ alloy at uniaxial tension loading using in situ electron backscattered diffraction (EBSD). The twinning, the basal $\langle a\rangle$ dislocation or $\langle c+a\rangle$ non-basal slips will be characterized, and the correlation between initial microstructure and deformation models is discussed.

\section{Experimental}

The material studied in the current work is $\mathrm{Mg}-0.5 \mathrm{wt} \% \mathrm{Ce}$ magnesium alloy rods (marked as $\mathrm{Mg}-\mathrm{Ce}$ alloy) prepared by hot extrusion. The microstructure evolution of the sample 
during tensile test was observed by in situ EBSD. A microtest system provided by Deben UK Limited with a load cell of $5 \mathrm{kN}$ capacity, installed inside a LEO ${ }^{\mathrm{TM}} 1450$ scanning electron microscope (SEM) fitted with a TSL ${ }^{\mathrm{TM}}$ EBSD camera, was used for the experiments. Figure 1 shows the schematic view of the in situ tensile test and the stress-strain curve during test. The tensile direction (TD) is parallel to the extrusion direction (ED) of the sample. Polishing was done before in situ tensile test on the observation planes of tension samples using a sequence of ethanol-based diamond suspensions of 6,3 and $1 \mu \mathrm{m}$, respectively. This was followed by fine polishing using colloidal silica suspension (OPS) and a final 2-4 s etching using a solution of $5 \% \mathrm{HNO}_{3}, 15 \%$ acetic acid, $20 \% \mathrm{H}_{2} \mathrm{O}$ and $60 \%$ ethanol before SEM and EBSD observations. The sample was tensional at room temperature at the displacement rate of $0.1 \mathrm{~mm} / \mathrm{s}$, corresponding to a strain rate of $0.0005 \mathrm{~s}^{-1}$, and the polished surface of the sample was tilted by $70^{\circ}$ to face the EBSD detector. The tensile test was carried out in steps. EBSD patterns from the same area of the sample surface were collected by stopping loading at extension intervals of $0.1 \mathrm{~mm}$ and holding the sample under load for the duration of the EBSD data collection, typically lasting $30 \mathrm{~min}$. The loading was stopped at the strain of $23 \%$ due to the weakening Kikuchi pattern with the increasing stain.

After the data collection in EBSD, dates with confidential index (CI) value $>0.3$ have been taken into account for data analysis by OIM software, and the inverse pole figure (IPF) map, band contrast map and the (0001), (10-10), (1-210) and (11-2-2) pole figures of same area in the sample were processed. To permit identification of active slip systems, the slip trace inclination to the tensile direction was measured from SEM micrographs after tensile strain 23\%, and the crystallographic orientation was determined by EBSD

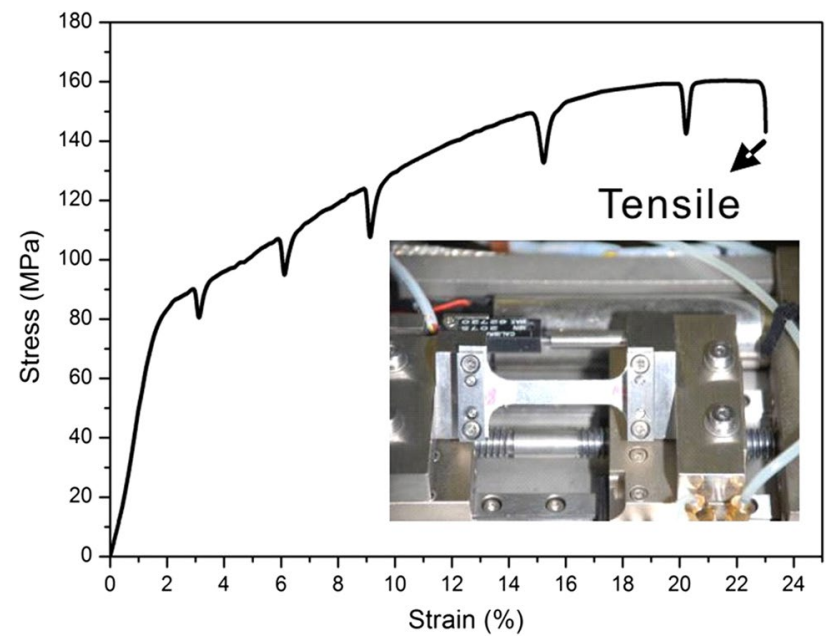

Fig. 1 Stress-strain curve of $\mathrm{Mg}-\mathrm{Ce}$ alloy during in situ tensile loading mapping. Twinning in grains $1-5$ and dislocation slip in grains A-K were examined totally (see Fig. 2 for the initial microstructures). The twinning boundaries are marked red, green or blue depending on the rotation of the lattice across the twin boundary. Extension twin boundaries $\left(86^{\circ}<1-\right.$ $\left.210> \pm 5^{\circ}\right)$, contraction twin boundaries $\left(56^{\circ}<1-210> \pm 5^{\circ}\right)$ and double twin boundaries $\left(38^{\circ}<1-210> \pm 5^{\circ}\right)$ are outlined in red, green and blue, respectively.

\section{Results and Discussion}

Figure 1 shows the stress-strain curves of $\mathrm{Mg}-\mathrm{Ce}$ alloy under in situ (interrupted) tensile test conditions. The applied stresses at strain of 3\%,6\%,15\%,20\% and 23\% dropped down where the loading had been stopped for data collection in EBSD. The strain hardening behavior in the sample is similar as that for $\mathrm{Mg}-\mathrm{Ce}$ alloy [2], suggesting that the grain structure evolution obtained from the in situ EBSD could be representative of the microstructure evolution during uninterrupted testing.

Figure 2 shows the IPF maps of Mg-Ce alloy at strains of 0,3\%,6\%, 15\%, 20\% and 23\%, and Fig. 3 shows the Kikuchi band contrast maps with characterized twins at strains of 0 , $6 \%$ and $15 \% .\{10-12\}$ twining was identified in grain 1 to grain 5 at strain of $6 \%$ according to the IPF map (Fig. 2b) and the contrast map (Fig. 3b), where $\{10-12\}$ twin boundaries were outlined by red line. Those twins will grow with increasing strain. Few $\{10-11\}-\{10-12\}$ double twins and \{10-11\} contraction twins were also observed on the sample at strain of 3\%,6\% and 15\% (Fig. 3), but double twins and contraction twins always appear thin and long [16], and then, the relative frequencies of the twins were not able to be determined. Besides, the increasing misorientation with increasing strain in grains in the IPF maps suggests that dislocation slips were operated in most grains. The deformation resulted in the rough smooth and then low EBSD indexing rates [17]. More black areas $(\mathrm{CI}<0.3)$ appear in Fig. 2 with increasing tensile strain.

Figure 4 shows the SEM micrographs of the $\mathrm{Mg}-\mathrm{Ce}$ alloy at strain of $23 \%$, and the slip trace in grains A-K was measured from the SEM images. Figure 4 also shows the crystallographic orientations of grains $\mathrm{A}-\mathrm{K}$ which were determined by EBSD mapping as shown in Fig. 2a, and the ideal trace of the intersection of the basal, prismatic and pyramidal planes was inspected in the pole figure for each grain, and after comparing the ideal trace with the slip trace on the grain surface, the possible slip systems were determined and Fig. 4 only provides the pole figures of the slip plane for the grain A to grain K. For example, only $\{10-11\}$ pole figure of grain $\mathrm{C}$ was provided here because the dislocation slip occurred on its (10-11) plane. The results suggested that the basal slip was activated in grains B, D and E and the dislocation slip 

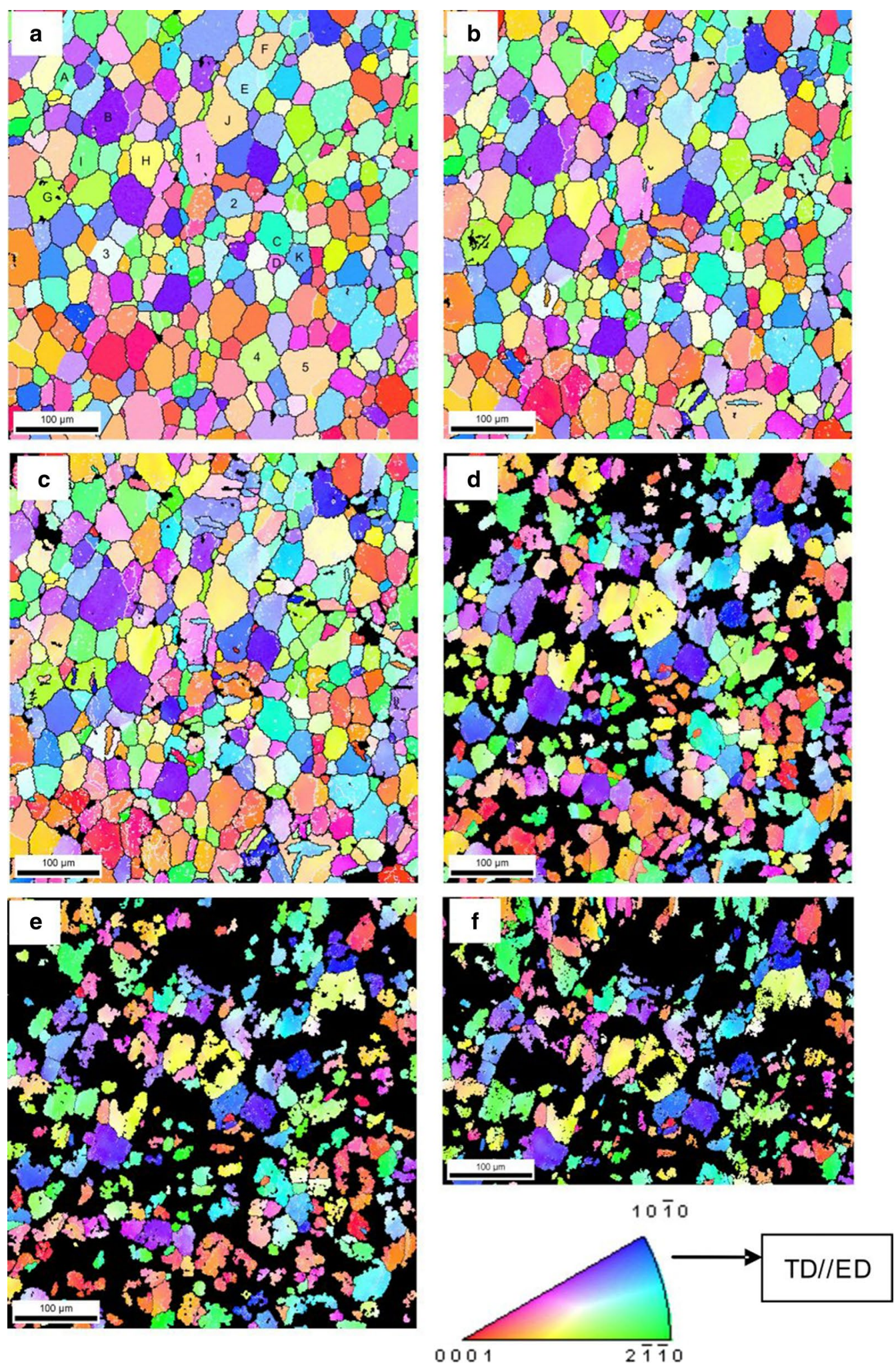

Fig. 2 IPF maps of Mg-Ce alloy at different tensile strains of a $0, \mathbf{b}$ $3 \%$, c $6 \%$, d $15 \%$, e $20 \%$, f $23 \%$. The tensile direction (TD) is paralthe orientations of the normal direction of the grains according to the color key. And those grains and boundaries in which its CI value is lower than 0.3 in the data collection were shown as black 


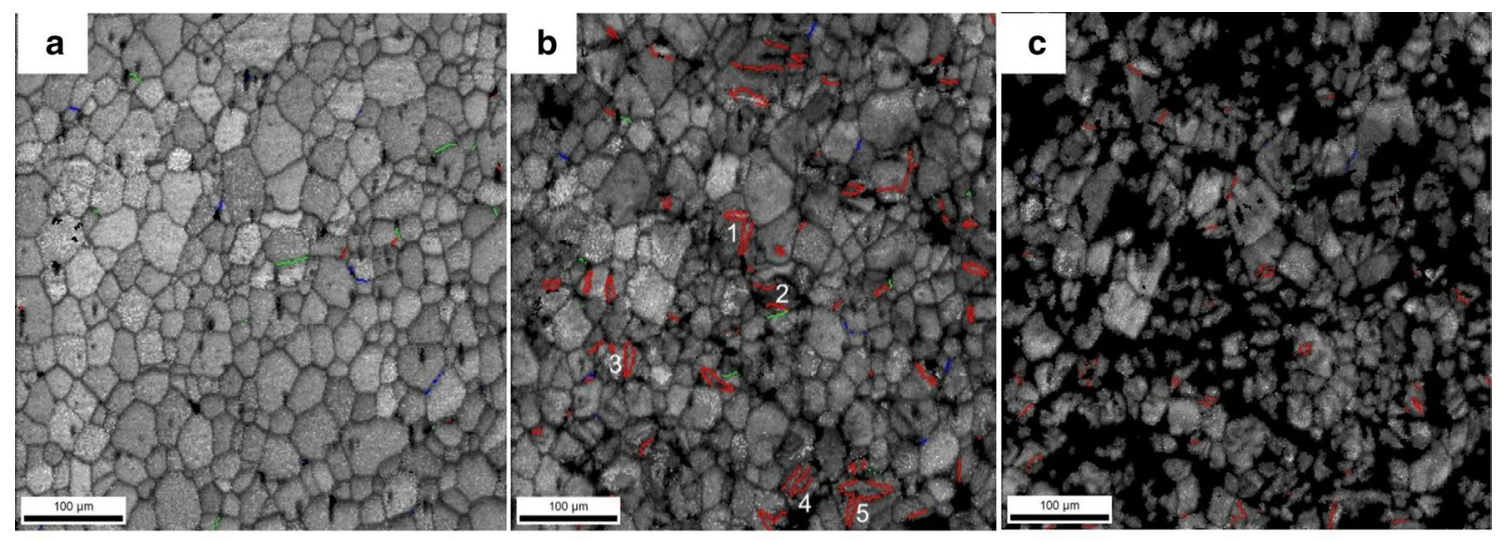

\begin{tabular}{|c|c|c|c|c|c|c|c|c|}
\hline \multicolumn{6}{|c|}{ Color key } & (a) & (b) & (c) \\
\hline \multicolumn{9}{|c|}{ Boundaries: Axis Angle } \\
\hline & Plane Normal & Direction & Angle & Tolerance & Phase & Fraction & Fraction & $\underline{\text { Fraction }}$ \\
\hline 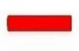 & $1-210$ & $\overline{1-210}$ & $86^{\circ}$ & $\overline{5^{\circ}}$ & $\overline{\text { Magnesium }}$ & $\overline{0.001}$ & 0.059 & $\overline{0.023}$ \\
\hline 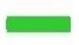 & $1-210$ & $1-210$ & $56^{\circ}$ & $5^{\circ}$ & Magnesium & 0.005 & 0.003 & 0.000 \\
\hline 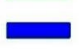 & $1-210$ & $1-210$ & $38^{\circ}$ & $5^{\circ}$ & Magnesium & 0.003 & 0.003 & 0.001 \\
\hline
\end{tabular}

Fig. 3 Kikuchi band contrast maps of $\mathrm{Mg}-\mathrm{Ce}$ alloy after strain of a 0, b $6 \%$, c $15 \%$. Color key for image quality map: the $\{10-12\}$ extension twin boundaries $\left(86^{\circ}<1-210> \pm 5^{\circ}\right)$ are outlined in red, the $\{10$ -

on (10-11) plane was activated in grains $\mathrm{C}, \mathrm{G}$ and $\mathrm{H}$, and the dislocation slip on (11-22) plane was activated in grains $\mathrm{A}$, $\mathrm{J}$ and I. In grain $\mathrm{K}$, no slip trace was observed and the deformation occurred on the grain boundaries supported by the voids on the grain boundaries between grain $\mathrm{K}$ and its neighbor grains. The SEM micrographs also show that the surface was roughened after tension deformation. Except for the slip trace in the grain interior, most displacement of the surface occurred along the original grain boundaries.

$\{10-12\}$ extension twinning, $\{10-11\}$ contraction and $\{10-11\}-\{10-12\}$ double twinning are the most possible twinning models in the deformation of magnesium alloy, and at the tension loading, contraction and double twinning are preferred for lot of commercial magnesium alloy, such as AZ31 [18], because there is contraction along the $c$-axis when typical ring basal texture exists in the AZ31 alloy [19]. At this loading condition, few contraction and double twinning were observed in the $\mathrm{Mg}-0.5 \% \mathrm{Ce}$ alloy according to the Kikuchi band map in Fig. 3b. And the volume fraction of twinning in this sample is quite low, and most of them are $\{10-12\}$ extension twinning. There are two possible reasons responsible for the low twinning volume fraction. Firstly, the main texture of the $\mathrm{Mg}-\mathrm{Ce}$ alloy showed that the $c$-axis has near $65^{\circ}-75^{\circ}$ with the ED (Fig. 4a), and few grains have their $c$-axis under contraction, and the CRSS for contraction twinning is much higher than that for extension twinning [20]; therefore, dislocation slip and few extension twinning are suppressed under this loading condition. Secondly, the
$11\}$ contraction twin boundaries $\left(56^{\circ}<1-210> \pm 5^{\circ}\right)$ outlined as green and the $\{10-11\}-\{10-12\}$ double twins boundaries $\left(38^{\circ}<1-210> \pm 5^{\circ}\right)$ outlined as blue

contraction and double twinning always were observed at higher strain deformation due to the higher CRSS, but it was difficult to index the twinning boundaries by EBSD mapping with increasing strain. However, we still can confirm that there was low volume fraction of contraction and double twins in this $\mathrm{Mg}-\mathrm{Ce}$ alloy compared to other alloys with ring basal texture because more slip systems were activated at this loading condition.

Slip on basal $(0001)<11-20>$ and $\{10-12\}<-1011>$ extension twinning were considered as dominant deformation models in the deformation of magnesium at room temperature. As mentioned before, the increasing ductility in $\mathrm{Mg}-\mathrm{Ce}$ alloy was ascribed to high Schmid factor value on basal slip [3]. In this observed area of $\mathrm{Mg}-\mathrm{Ce}$ alloy, slips on basal, pyramidal $\{10-11\}$ and $\{11-22\}$ planes were determined together (Fig. 4) and the fraction of each slip is close to each other, but no $\{10-10\}$ slip was observed in the observed grains. Those non-basal slips accommodate straining in the $c$-direction and improve the deformation compatibility of the $\mathrm{Mg}-\mathrm{Ce}$ alloy. Prismatic $\{10-10\}<11$ $20>$ and pyramidal $\{10-11\}<11-20>$ and also $<c+a>$ slip $\{11-22\}<-1-123>$ had been thought as an accommodation mechanism [21] for magnesium alloy at room and elevate temperatures, but the fraction of non-basal slip by total strain is quite low in most wrought alloy. Figure 4 shows the equivalent fraction of non-basal slip compared to basal slip in those observed grains $\mathrm{A}-\mathrm{K}$ of $\mathrm{Mg}-\mathrm{Ce}$ alloy, which suggests that $\mathrm{Ce}$ addition somehow changes the activation 

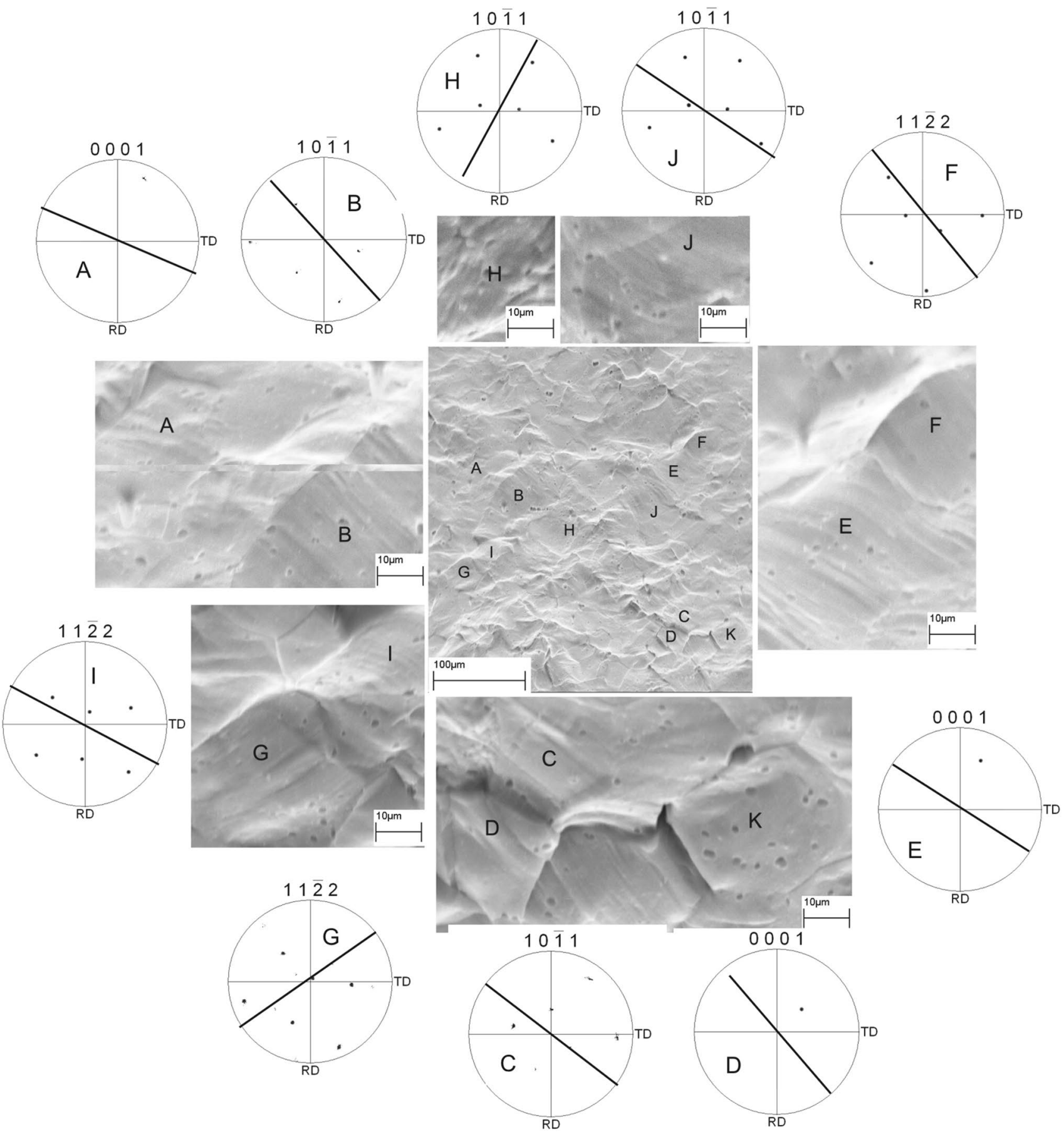

Fig. 4 Slip traces and accompanying pole figures illustrating the method used to identify the most likely active deformation mode after strain of $23 \%$. The line on the pole figures corresponds to the trace of the slip plane (arrowed pole) closest to the observed slip trace

of deformation modes on the pyramidal planes in Mg. And recently, study on $\mathrm{Mg}-\mathrm{Y}$ alloy also reported a high occurrence of $\langle c+a\rangle$ slip and increased activation of compression/secondary twins $[7,15]$. But the actual reason for this higher activation remains unclear. In our previous work, the segregation of $\mathrm{Gd}$ near dislocation core could be ascribed to the obstacle of dislocation slip on basal system and then promoted the activation of non-basal slip [22], and in the study of $\mathrm{Mg}-\mathrm{Li}$ single crystal deformation at room temperature, evidence for $\langle c+a\rangle$ slip was also found [23] which ascribed to $c$-axis/ $a$-axis ratio changed by Li element addition [24] and lower CRSS of $\langle\boldsymbol{c}+\boldsymbol{a}\rangle$ slip than $\{10-10\}\langle\boldsymbol{a}\rangle$ slip [23]. Having no evidence to support that the $c$-axis/aaxis ratio was changed with the Ce addition so far, however, 
there is still possible reason to believe that some physical properties of the $\mathrm{Mg}-\mathrm{Ce}$ solute had been changed by $\mathrm{Ce}$ addition, such as the stacking fault of on basal and non-basal plane of $\mathrm{Mg}$, which resulted in the changing of CRSS on non-basal plane. More investigated methods should be taken into account to clear the mechanism.

\section{Conclusions}

The in situ EBSD work shows few $\{10-12\}$ extension twinning happened in $\mathrm{Mg}-0.5 \mathrm{wt} \% \mathrm{Ce}$ alloy under tensile deformation. Contraction and double twinning are less than extension twinning at low strain. Besides basal slip and extension twinning, the trace analysis and EBSD data provide evidence for the operation of $\{10-11\}$ and $\{11-22\}$ slip, which contribute to the weakening of texture and the increase in ductility at room temperature of $\mathrm{Mg}-0.5 \mathrm{wt} \% \mathrm{Ce}$ binary alloy as well.

Acknowledgements The authors gratefully acknowledge the financial supports of the National Key Research and Development Plan (Grant Nos. 2016YFB0301103 and 2016YFB0701201) and the National Natural Science Foundation of China (Grant Nos. 51771109 and 51631006).

\section{References}

[1] X.J. Wang, D.K. Xu, R.Z. Wu, X.B. Chen, Q.M. Peng, L. Jin, Y.C. Xing, Z.Q. Zhang, Y. Liu, X.H. Cheng, G. Chen, K.K. Deng, H.Y. Wang, J. Mater. Sci. Technol. 34, 245 (2018)

[2] L.W.F. Mackenzie, M.O. Pekguleryuz, Scr. Mater. 59, 665 (2008)
[3] R.K. Mishra, A.K. Gupta, P.R. Rao, A.K. Sachdev, A.M. Kumar, A.A. Luo, Scr. Mater. 59, 562 (2008)

[4] D.H. Kim, F. Ebrahimi, M.V. Manuel, J.S. Tulenko, S.R. Phillpot, Mater. Sci. Eng. A 528, 5411 (2011)

[5] L.W.F. Mackenzie, B. Davis, F.J. Humphreys, G.W. Lorimer, Mater. Sci. Technol. Lond. 23, 1173 (2007)

[6] K. Hantzsche, J. Bohlen, J. Wendt, K.U. Kainer, S.B. Yi, D. Letzig, Scr. Mater. 63, 725 (2010)

[7] H. Yan, R.S. Chen, E.H. Han, Mater. Sci. Eng. A 527, 3317 (2010)

[8] S. Sandlöbes, S. Zaefferer, I. Schestakow, S. Yi, R. GonzalezMartinez, Acta Mater. 59, 429 (2011)

[9] W.X. Wu, L. Jin, Z.Y. Zhang, W.J. Ding, J. Dong, J. Alloys Compd. 585, 111 (2014)

[10] N. Stanford, D. Atwell, A. Beer, C. Davies, M.R. Barnett, Scr. Mater. 59, 772 (2008)

[11] T. Mukai, M. Yamanoi, H. Watanabe, K. Higashi, Scr. Mater. 45, 89 (2001)

[12] M.H. Yoo, Metall. Trans. A 12, 409 (1981)

[13] J. Koike, T. Kobayashi, T. Mukai, H. Watanabe, M. Suzuki, K. Maruyama, K. Higashi, Acta Mater. 51, 2055 (2003)

[14] Y. Chino, M. Kado, M. Mabuchi, Acta Mater. 56, 387 (2008)

[15] L.Y. Wang, Z.H. Huang, H.M. Wang, A. Maldar, S.B. Yi, J.S. Park, P. Kenesei, E. Lilleodden, X.Q. Zeng, Acta Mater. 155, 138 (2018)

[16] R.E. Reed-Hill, Trans. Metall. Soc. AIME 218, 554 (1960)

[17] Z. Keshavarz, M.R. Barnett, Scr. Mater. 55, 915 (2006)

[18] G.S. Songa, S.H. Zhanga, L. Zheng, L.Q. Ruan, J. Alloys Compd. 509, $6481(2011)$

[19] L. Jiang, J.J. Jonas, R.K. Mishra, A.A. Luo, A.K. Sachdev, S. Godet, Acta Mater. 55, 3899 (2007)

[20] M.R. Barnett, Metall. Mater. Trans. A 34, 1799 (2003)

[21] S.R. Agnew, Ö. Duygulu, Int. J. Plast. 21, 1161 (2005)

[22] Y.X. Li, J. Wang, K. Chen, M.Y. Shao, Y. Shen, L. Jin, G.Z. Zhu, Sci. Rep. 6, 38537 (2016)

[23] S. Ando, H. Tonda, Mater. Trans. JIM 41, 1188 (2000)

[24] R.S. Busk, Trans. AIME 188, 1460 (1950) 